\title{
A novel sediment microbial fuel cell with a biocathode in the rice rhizosphere
}

\author{
Zheng Chen $^{\mathrm{a}, 1}$, Yan-chao Huang ${ }^{\mathrm{a}, 1}$, Jian-hong Liang ${ }^{\mathrm{a}}$, Feng Zhao ${ }^{\mathrm{b}}$, Yong-guan Zhu ${ }^{\mathrm{a}, \mathrm{b}, *}$ \\ ${ }^{a}$ Research Center for Eco-Environmental Sciences, Chinese Academy of Sciences, Beijing 100085, China \\ ${ }^{\mathrm{b}}$ Institute of Urban Environment, Chinese Academy of Sciences, Xiamen 361021, China
}

\section{A R T I C L E I N F O}

Article history:

Received 9 August 2011

Received in revised form 11 October 2011

Accepted 12 October 2011

Available online 20 October 2011

\section{Keywords:}

Microbial fuel cells

Wetland plant

Radius oxygen loss

Rice

Biocathode

\begin{abstract}
A B S T R A C T
Wetland plants possess the unique ability to release oxygen as well as organic matter into the rhizosphere. It is understood that microbial fuel cells (MFCs) can use organic matter from plants as key electron donors, but the effect of root excreted oxygen on MFCs is presently unknown. In this study, a novel biocathode was buried in the rice rhizosphere and found to be capable of delivering electrons to root excreted oxygen for oxygen reduction reactions. The voltages between electrodes in the rhizosphere and bulk soil were found to increase initially, but dissipate after approximately 1 month. Results from the MFC and oxygen microelectrode experiments indicated that the oxygen efflux rate from rice roots was dependent on the root maturity. Furthermore, the excreted oxygen from wetland plant roots could be used for the construction of highly efficient biocathodes.
\end{abstract}

(c) 2011 Elsevier Ltd. All rights reserved.

\section{Introduction}

The environmentally-friendly conversion of biomass into energy is essential to produce both sustainable and renewable energy for the future. However, sugars and proteins in biomass (e.g. plant seeds or tubes) are presently part of the world's food supply. Other biomass, such as dead roots and shoot residues, are currently underutilized and left to decay naturally in fields where they support abundant microbial activities in the soil (Marschner et al., 2003). This neglected plant material has been recognized as an excellent source of biomass for bio-energy production. Among the present technologies able to transfer inedible biomass to energy, sediment microbial fuel cells (SMFCs) offer several unique advantages. SMFCs have a low environmental impact because they can transform organic matter into electrical energy without the transportation of biomass (Lovley, 2006).

This technology is classified as a type of photosynthetic microbial fuel cells (Rosenbaum et al., 2010). A typical SMFC with plants is constructed with an anode buried in reduced, flooded soil and a cathode placed at the air-water interface where it uses either oxygen reduction or other oxidizing chemicals. Electricity is then generated by the bacteria that oxidize the organic matter from soils or plant roots and release electrons (De Schamphelaire et al., 2008; Kaku et al., 2008).

\footnotetext{
* Corresponding author at: Research Center for Eco-Environmental Sciences, Chinese Academy of Sciences, Beijing 100085, China. Tel.: +86 10 62936940; fax: +861062923563.

E-mail address: ygzhu@rcees.ac.cn (Y.-g. Zhu).

1 These authors contributed equally to this study.
}

In an SMFC with plants, wetland plants play a key role in supplying organic matter to the anode reaction (De Schamphelaire et al., 2008). As the most widely cultivated wetland plant, rice was used in initial studies on SMFCs with plants to supply organic matter for bacteria in anodes (De Schamphelaire et al., 2008; Kaku et al., 2008). Other plants, such as Spartina anglica and Arundinella anomala, were also able to supply organic matter for bio-energy production (Helder et al., 2010; Timmers et al., 2010). The SMFC with plants is considerably more complex than other MFC systems designed for wastewater treatment due to the added variable of plant growth. The factors influencing power generation by SMFCs are not yet well understood.

To adapt to anaerobic conditions in flooded fields, aerenchyma is developed in aquatic plants to allow for the downward transport of oxygen which can then facilitate a robust metabolism in wetland plant roots (Armstrong et al., 1991). The oxygen secreted from roots forms a micro-oxidizing environment in the rhizosphere. By using microelectrodes embedded in soil or sediment, early studies showed that the redox values reach up to $100 \mathrm{mV}$ at the root tips (Flessa and Fischer, 1992). Recently, coupling with digital image analysis and rhizotron allowed for a rough depiction of the oxidized and reduced zones using 18 platinum electrodes (Schmidt et al., 2010). The micro-oxidizing zone was shown to extend $8 \mathrm{~mm}$ along the wetland plant roots (Frederiksen and Glud, 2006). This zone has been shown to influence greenhouse gas production (Segers, 1998; Van Bodegom et al., 2001) and the bioavailability of toxic elements (Chen et al., 2004; Liu et al., 2004). For SMFCs with plants, plant roots were often found to have penetrated through the buried anode (Kaku et al., 2008). As a result, the oxygen flux into the rhizosphere may worsen the anode 
performance and, as a consequence, the cell potential (Timmers et al., 2010).

Cathode reactions sometime become a limitation for MFC power generation due to activation, ohmic and mass transport losses (Rismani-Yazdi et al., 2008; Zhao et al., 2009). To reduce cathodic loss, electron mediators or oxidizing bacteria biocatalysts have been applied to MFCs and were found to yield much higher energy densities (De Schamphelaire et al., 2008). However, mediators require regular addition and may cause health problems, which is an unsuitable choice for sustainable power generation. Biocathodes with oxidizing bacteria are a good alternative because of their low costs and good operational sustainability (He and Angenent, 2006). In the wetland plant rhizosphere, iron oxidizing bacteria are abundant and found to be associated with iron plaques (Emerson et al., 1999; Weiss et al., 2011). However, the use of roots and iron oxidizing bacteria in the construction of biocathodes for SMFCs has never been done.

Here, a proof-of-concept experiment was conducted to test whether the root-contacting electrode buried in a rice paddy soil could accept electrons from rhizosphere oxygen. Estimates of the amount of oxygen released from rice roots were also made using the MFC cathode as an oxygen sensor. To do so, a novel SMFC with two cathodes was designed. One cathode was placed in the rhizosphere and another was fixed at the air-water interface. The voltages between the two cathodes and an anode were monitored during the plant growth season.

\section{Methods}

\subsection{Plant pre-cultivation}

Rice (Oryza sativa L.) cultivar Jiahua No. 1 was selected. Seeds were sterilized by immersion in $10 \% \mathrm{H}_{2} \mathrm{O}_{2}$ for $15 \mathrm{~min}$, followed by germination in humid perlite. Before being transplanted into the SMFC apparatus, the seedlings were grown in a hydroponic culture in a climate-controlled room until the fourth leaf expanded (ca. 20 days). The room conditions were set at $25^{\circ} \mathrm{C}$ in daylight $\left(14 \mathrm{~h}, 180 \mu \mathrm{E} \mathrm{m}^{-2} \mathrm{~s}^{-1}\right)$ and $20^{\circ} \mathrm{C}$ in dark $(10 \mathrm{~h})$.

\subsection{SMFC set-up}

An SMFC apparatus was employed that consisted of a $50 \mathrm{ml}$ centrifuge tube housed inside a lightproof plastic container $(14 \mathrm{~cm} \times 10 \mathrm{~cm})$ (Fig. 1). The container was filled with fresh paddy soil collected from Jiaxing, Zhejiang province, China to a height of $10 \mathrm{~cm}$. A round, $3 \mathrm{~mm}$ thick graphite mat $(10 \mathrm{~cm}$ diameter, $78 \mathrm{~cm}^{2}$ geometric area; Beijing Sanye Carbon Co. Ltd., Beijing, China) was placed $10 \mathrm{~mm}$ from the bottom of the container. Before transplanting, the paddy soil and pre-placed graphite mat were flooded for 1 month to stabilize the anode without connection resistance.

A $50 \mathrm{ml}$ centrifuge tube with two graphite mats was placed into a root-sleeving electrode and half-inserted into the soil in the container. The conical bottom of the tube was cut off and holes (ca. 1 hole per $4 \mathrm{~mm}^{2}$ ) were punctured into the tube wall using pins. The holes allowed for the passage of soil solution through the tube wall. One square graphite mat ( $3 \mathrm{~mm} \times 30 \mathrm{~mm} \times 97 \mathrm{~mm})$ served as the air cathode and was fixed on the top of the tube. Another graphite mat ( $3 \mathrm{~mm} \times 30 \mathrm{~mm} \times 84 \mathrm{~mm})$ was rolled and attached on the internal surface of the bottom of the tube. The graphite mat buried in the soils acted as the soil cathode in the cells.

Two rice seedlings were planted in the tubes. Rice roots were anticipated to expand along the tube wall and be in close contact with the soil cathodes. All of the electrodes were clean and used as received; they were conducted out with titanium wires.

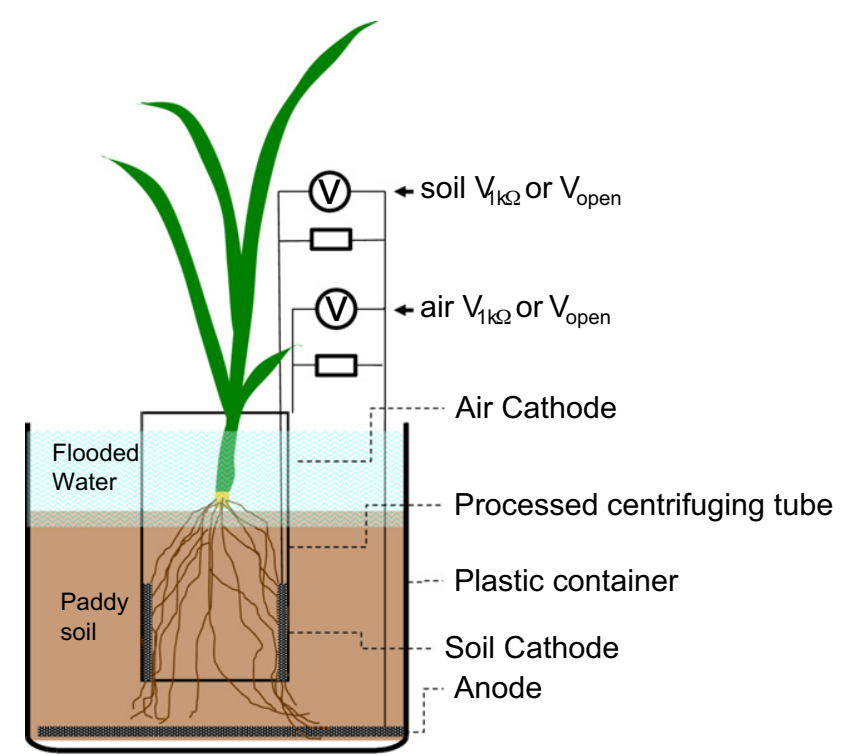

Fig. 1. Section plan of the experimental setup of the SMFC with air cathode and soil cathode. The anode was a round graphite mat, and two cathodes were tube-like shape by bending rectangle graphite mats. $V_{1 \mathrm{k} \Omega}$ : the voltage between two electrodes with $1000 \Omega$ resistance; $V_{\text {open }}$ : the voltage between two electrodes without resistances.

\subsection{SMFCs without an activated anode}

Eight SMFC apparatuses were constructed. Two controls were used. One control consisted of an open circuit, and the other was a closed circuit with a connection of $1000 \Omega$ resistance. Any plant grown in the control was quick removed when observed. For the treatments, four seedlings were planted in each container. Two of them were planted in the tube; the others were beside them. No fertilizer was added to the soils, plants were irrigated with deionized water. Among the six SMFCs with plants, two were in open circuits and the other four were connected with $1000 \Omega$ resistance. All of the voltages were recorded using a data logger (USB7660, ZTIC Co., Beijing, China).

\subsection{SMFC with an activated anode}

Six cells from experiments described in Section 2.3 were incubated in the climate-controlled room for 56 days to allow for anode activation (Table S1). During the activation, no plant or organic matter was added to the cell, but native algae (mostly Spirogyra) were found in the surface water.

The cells were moved to a greenhouse after the activation. Among the six cells, three were planted with two rice seedlings into the root-sleeving tubes. The others and the controls consisted of two cells in a closed circuit or in an open circuit. Around $30 \mathrm{~g}$ of dry paddy soils, mixed with urea $\left(0.2 \mathrm{~g} \mathrm{~kg}^{-1}\right.$ as $\left.\mathrm{N}\right), \mathrm{CaHPO}_{4} \cdot 2 \mathrm{H}_{2} \mathrm{O}$ $\left(0.15 \mathrm{~g} \mathrm{~kg}^{-1}\right.$ as $\left.\mathrm{P}_{2} \mathrm{O}_{5}\right), \mathrm{K}_{2} \mathrm{SO}_{4}\left(0.2 \mathrm{~g} \mathrm{~kg}^{-1}\right.$ as $\left.\mathrm{K}_{2} \mathrm{O}\right)$, was added into the root-sleeving tube to support the plant growth. On day one, root-sleeving tubes with seedlings were half inserted into the soil and subsequently topped with $4 \mathrm{~cm}$ of deionized water (Fig. 1). For these flooded samples, the root and air cathodes were adapted to the new set of conditions. The soil cathodes were incubated in a mixture of soil, solution and air, while the air cathodes were fixed at the interface between the solution and air. On day $20,10 \mathrm{ml}$ of nutrition solution $\left(7.5 \mathrm{mM} \mathrm{N}\right.$ as $\mathrm{NH}_{4} \mathrm{NO}_{3}, 4 \mathrm{mM} \mathrm{K}$ as $\mathrm{K}_{2} \mathrm{SO}_{4}$ and $1.5 \mathrm{mM} \mathrm{P}$ as $\mathrm{NaH}_{2} \mathrm{PO}_{4}$ ) was injected into the root-sleeving tube by a syringe. Three hours later, another $10 \mathrm{ml}$ of nutrition solution that had been deoxygenated by purging with $\mathrm{N}_{2}$ for 30 min was 
injected. A variety of $10 \mathrm{ml}$ solutions were then injected including 1.5 mM P solution (day 22), deionized water (day 26), $1.5 \mathrm{mM} \mathrm{P}$ solution (day 27), $4 \mathrm{mM}$ K solution (day 28), and 7.5 mM N solution (day 29).

\subsection{Net oxygen flux measurement}

Net oxygen flux on root surfaces was detected using the scanning ion-selective electrode technique system (BIO-001A; Younger USA LLC). The seedlings used for oxygen flux measurements were grown under the same conditions as described above. The plants were transferred into a measuring chamber filled with a hypoxic solution (Pang et al., 2006). One mature root was selected and fixed on the chamber to prevent floating. The positions of the microelectrode and camera were adjusted to insure the $\mathrm{O}_{2}$-probe tip was adjacent to the root surface $\left(<10 \mu \mathrm{m}\right.$ away). The $\mathrm{O}_{2}$ microelectrode tip slowly vibrated (amplitude: $30 \mu \mathrm{m}, 0.3-0.5 \mathrm{~Hz}$ ) while away from the root surface using a computer-driven micromanipulator. Electrode movement did not disturb the solution. Net oxygen flux was determined in a steady-state environment for $3 \mathrm{~min}$ at one position. Nitrogen gas was bubbled into the solution for $5 \mathrm{~min}$ between two measurements to insure hypoxia condition. When the root was replaced, the solution was also replaced. All experiments were accomplished by Xuyue Sci. and Tech. Co. Ltd.

\section{Results and discussion}

\subsection{Voltage fluctuation during plant growth}

Towards better description, the abbreviations used in this study were explained in Table 1 . In the first trial, the highest $V_{1 \mathrm{k} \Omega}$ detected in the cells $(102 \mathrm{mV})$ was calculated using the air cathode in the control (Table S2), which was equivalent to $1.3 \mathrm{~mW} \mathrm{~m}^{-2}$. The low electricity produced by the cells with $1000 \Omega$ resistances might be due to a paucity of electrogenic bacteria on the anode surface. Rice plants were found to have an influence on the soil cathode. Significant positive soil $V_{1 \mathrm{k} \Omega} \mathrm{S}$ were recorded for more than 30 days when rice was planted in the root-sleeving tube (Table S2), which implies that there was continual oxygen excretion from the rice roots.

The activation of the anode for 56 days resulted in an increase and stabilization of the cell voltages. As shown in Fig. 2, the air $V_{\text {open }}$ of the cell without plants rapidly increased and oscillated between 500 and $708 \mathrm{mV}$, at the same time, the soil $V_{\text {open }}$ decreased quickly and became negative in $22 \mathrm{~h}$. After reaching a minimum of $-201 \mathrm{mV}$, the soil $V_{\text {open }}$ exhibited a positive linear relationship with time. A similar tendency was also found when the circuits of the cells were connected with external resistance (Fig. 2). The air $V_{1 \mathrm{k} \Omega}$ varied from 125 to $248 \mathrm{mV}$, and the soil $V_{1 \mathrm{k} \Omega}$ linearly increased from -38 to $-24 \mathrm{mV}$ from days 2 to 21 following an initial.

Due to the degradation of aquatic organisms and diffusion of atmospheric oxygen, top soil generally contains a higher concentration of organic matter and oxygen than soil at depth. The soil redox potential was often found to decrease with organic matter

Table 1

Abbreviations used to describe the voltage differences between electrodes. $V_{\text {open }}$ : open circuit voltage; $V_{1 \mathrm{k}}$ : closed circuit voltage with external resistance of $1000 \Omega$; air $V_{\text {open }}$ or $V_{1 \mathrm{k}}$ : the $V_{\text {open }}$ or $V_{1 \mathrm{k}}$ between air cathode and the anode; soil $V_{\text {open }}$ or $V_{1 \mathrm{k}}$ : the $V_{\text {open }}$ or $V_{1 \mathrm{k}}$ between soil cathode and the anode.

\begin{tabular}{llll}
\hline & Description & Cathode location & External resistance \\
\hline Air $V_{\text {open }}$ & Open circuit voltage & Water-air interface & No \\
Air $V_{1 \mathrm{k} \Omega}$ & Open circuit voltage & Water-air interface & $1000 \Omega$ \\
Soil $V_{\text {open }}$ & Open circuit voltage & Soil or rhizosphere & No \\
Soil $V_{1 \mathrm{k} \Omega}$ & Close circuit voltage & Soil or rhizosphere & $1000 \Omega$ \\
\hline
\end{tabular}

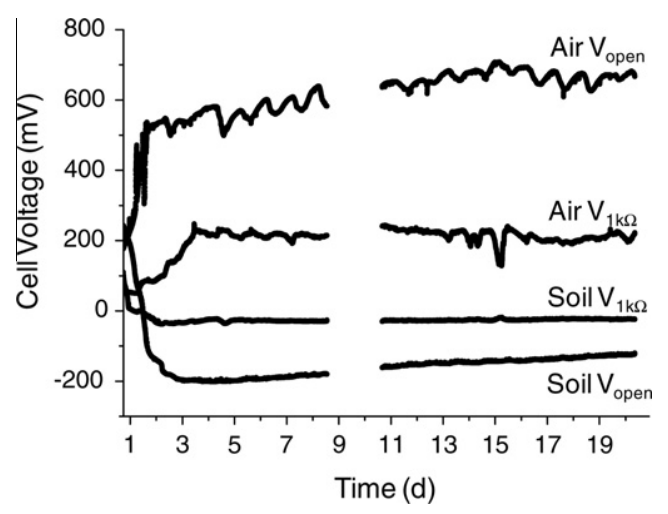

Fig. 2. The cell voltages fluctuation of sediment microbial fuel cell as a function of time. The data from days 8 to 10 were lost because of power-down.

decomposition (Tanji et al., 2003; Gao et al., 2011), and it was recently reported that slight amounts of oxygen can increase the anodic metabolic activity which may cause a higher electron pressure at the cathode compared to the anode (Ajayi et al., 2010). Thus, both causes may result in the cell electrodes' polarity reversion.

The presence of plants in the root-sleeving tube had minimal influence on the air $V_{\text {open }}$, but greatly affected the variation patterns of the air $V_{1 \mathrm{k} \Omega}$, soil $V_{1 \mathrm{k} \Omega}$ and soil $V_{\text {open }}$ (Fig. 3 and Fig. S1). The variation patterns could be divided into three stages. Initially, soil $V_{1 \mathrm{k} \Omega}$ and $V_{\text {open }}$ dropped near to or below zero from days 1 to 3 , respectively. At the same time, air $V_{1 \mathrm{k} \Omega}$ and $V_{\text {open }}$ increased and varied around 90 and $700 \mathrm{mV}$, respectively. The air $V_{\text {open }}$ then fluctuated above or below $800 \mathrm{mV}$. Stage two, from days 3 to 17, was characterized by the soil $V_{\text {open }}$ and $V_{1 \mathrm{k} \Omega}$ increasing and stabilizing. In this stage, the soil $V_{\text {open }}$ was slightly lower than the air $V_{\text {open. }}$ Moreover, the soil $V_{1 \mathrm{k} \Omega}$ was even higher than the air $V_{1 \mathrm{k} \Omega}$ from days 11 to 17 . The maximum voltages of an SMFC, $191 \mathrm{mV}$ of air $V_{1 \mathrm{k} \Omega}$ and $201 \mathrm{mV}$ of soil $V_{1 \mathrm{k} \Omega}$, were observed during this period. Following the stabilization period, the soil $V_{\text {open }}$ dramatically decreased from 780 to ca. $450 \mathrm{mV}$ and the soil $V_{1 \mathrm{k} \Omega} \mathrm{S}$ gradually declined from day 17.
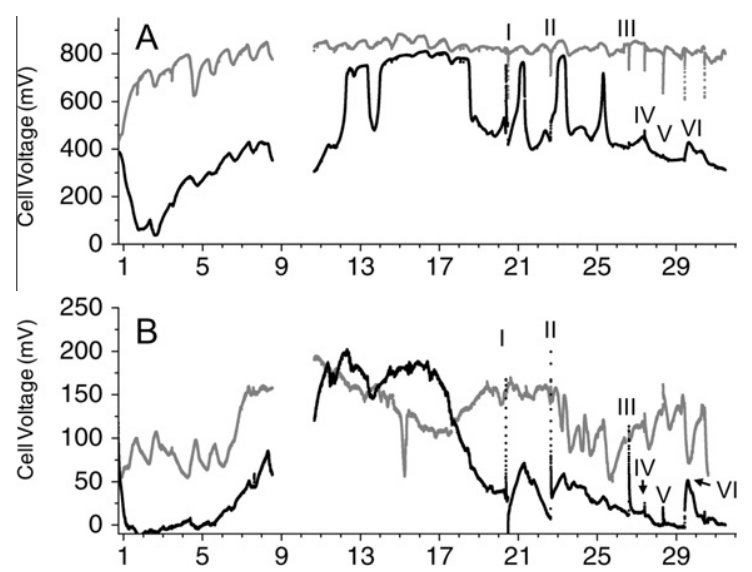

Fig. 3. The cell voltages fluctuation of SMFCs as a function of time. (A) Open circuit voltage; (B) voltage with $1000 \Omega$ external resistance. Gray lines represent the voltages between anode and air cathode, black lines represent the voltages between anode and soil cathode. The data from days 8 to 10 were lost because of powerdown. Peaks with Roman numbers means different solutions were injected into rhizosphere: (I) mixed nutrition solution and deoxygenated solution; (II) sole P; (III) DI water; (IV) sole P; (V) sole K; (VI) sole N. 


\subsection{Estimation of oxygen flux from rice roots}

In this study, the cathode of the SMFC was used as an oxygen sensor with continuous electrochemical signals being detected in situ. These signals were measured in the rhizosphere of the rice root for 32 days (Fig. 3B) and indicate that oxidized chemicals were reduced in the cathode reaction. Assuming the cathode half-reaction was $\mathrm{O}_{2}+2 \mathrm{H}_{2} \mathrm{O}+4 \mathrm{e}^{-}=4 \mathrm{OH}^{-}$, the oxygen depletion rate on the cathode was calculated based on the $V_{1 \mathrm{k} \Omega}$ curve (Fig. 3 ). The calculation was based on the equation: $N\left(\mathrm{O}_{2}\right) / t=I /(n F)$, where $I$ is the current, $n$ is the number of the electrons consumed to reduce $\mathrm{O}_{2}$, and $F$ is Faraday's constant $\left(96485 \mathrm{C} \mathrm{mol}^{-1}\right)$. The electrical current was calculated using ohm's law $I=V / R$, where $V$ is voltage and $R$ is the external resistance. Because no cathode reaction was observed in the control, the enhancement of the soil cathode's potential in the cells with plants must be due to the rice plants excreting oxygen. Thus, the oxygen depletion rate on the cathode could be used as a reliable estimate of the rate of rice root oxygen excretion.

In this study, the maximum daily oxygen depletion rate on the soil cathode of $20 \mu \mathrm{mol}$ plant $^{-1}$ day $^{-1}$ was recorded on day 15 . Planar optode is a two-dimensional oxygen mapping system with a luminescent indicator. This system has been used to investigate the oxygen dynamics in the rhizosphere of eelgrass Zostera marina (Frederiksen and Glud, 2006). An estimated total oxygen loss of $2.69 \mu \mathrm{mol} \mathrm{O}_{2}$ plant $^{-1}$ day $^{-1}$ was yielded by assuming $12 \mathrm{~h}$ in daylight and that oxygen was excreted from roots on the first two internodes. Although this estimate of oxygen loss from eelgrass is lower than the calculated oxygen flux value from the SMFC with rice plants, several facts imply that the calculated oxygen flux is underestimated in this study: (1) not all the oxidized material excreted from roots could reach the cathode surface; (2) the rice root only partially covered the cathode surface; (3) the rice root growth was restricted; and (4) the rice plants used in this study were juvenile. Thus, the efficiency of the rhizo-cathode was not optimal. The power density of the SMFC could be enhanced using a structure that separated the organic matter and oxidized material excreted out of the wetland plant roots.

\subsection{Causes of soil $V_{1 k \Omega}$ fluctuation}

When the soil $V_{1 \mathrm{k} \Omega}$ declined to $30 \mathrm{mV}$, which was $15 \%$ of the highest soil $V_{1 \mathrm{k} \Omega}$, nutrition solution was injected into the adjacent soil cathode (Fig. 3B). The first injection included a $10 \mathrm{ml}$ solution of $\mathrm{N}, \mathrm{P}$ and $\mathrm{K}$ which induced a sudden voltage peak of $167 \mathrm{mV}$. In the same day, a $10 \mathrm{ml}$ deoxygenated solution was injected and resulted in a voltage drop to $-9 \mathrm{mV}$ which quickly recovered. A wide peak of soil $V_{1 \mathrm{k} \Omega}$ was observed following the two injections. Sole element solution and deionized water were also added to investigate their effects. Many solutions changed the catholyte composition and led to a sharp or wide voltage peak, but none of them recovered the soil $V_{1 \mathrm{k} \Omega}$ to a level comparable to the air $V_{1 \mathrm{k} \Omega}$. Similar voltage changes were observed in another replicate (Fig. S1).

In the third stage, soil $V_{1 \mathrm{k} \Omega}$ and $V_{\text {open }}$ were found to decrease after approximately 1 month. Three hypotheses could explain this phenomenon. First, the oxygen reducing in the rhizosphere could be due to a lack of adequate mineral uptake by the rice roots which were restricted in the root-sleeving tubes (Trolldenier, 1973; Liu et al., 2004). Second, the oxygen excreted from the rice roots was not uniform along the roots (i.e. young rice roots were able to excrete more oxygen than the mature or aging rice roots) (Rubinigg et al., 2002; Kotula and Steudle, 2009). Third, over time microbial activity along the roots increased and microbes competed with the cathode for oxygen, effectively lowering the availability of oxygen on the root surface.

The first hypothesis was rejected by the fact that chemical fertilizer addition did not stop or delay the soil $V_{1 \mathrm{k} \Omega}$ decrease and no obvious symptoms of mineral deficiency were noted during the experiment (Fig. 3). Although the microbial communities in different stages in the rhizosphere soil and bulk soil were not directly investigated, the injection of nutrition solution and deionized water induced a voltage rise when the solution was oxygenated. This finding indicates that the voltage decrease in the third stage was mainly due to the decrease in oxygen on the cathode surface and not to changes in the microbial community. Interestingly, the peaks induced by the solution injections were short in duration even though the injected solutions were identical (see peaks (II) and (IV) in Fig. 3B). One explanation is that the microbial community responds slowly to changes in the redox environment (Yuan et al., 2009). Unlike the sharp peaks which may be induced by oxygen, the peaks after $\mathrm{NH}_{4} \mathrm{NO}_{3}$ addition were wide and may be the result of cathode microorganisms slowly using nitrate as an electron acceptor (Clauwaert et al., 2007).

A detailed oxygen flux pattern along the root length was discovered by placing oxygen microelectrodes near rice roots during hypoxic and stagnant solution conditions. Both influx and efflux of oxygen were found on the surface of adventitious root (Fig. 4). The root cap and meristem region $(0.15 \mathrm{~mm}$ behind root tip) consumed a considerable amount of oxygen at a rate of approximately $60 \mathrm{pmol} \mathrm{cm} \mathrm{cm}^{-2} \mathrm{~s}^{-1}$. Conversely, the elongation zone and maturation zone excreted oxygen, which reached its maximum at $20 \mathrm{~mm}$ from the tip ( $40 \mathrm{pmol} \mathrm{cm}^{-2} \mathrm{~s}^{-1}$ ). Weak oxygen efflux was then detected around adventitious roots above $60 \mathrm{~mm}$. When the cathode of the SMFC was used as an oxygen sensor, the maximum instant oxygen depletion rate on the soil cathode was $520 \mathrm{pmol} \mathrm{s}^{-1}$. This rate was calculated using the highest value of soil $V_{1 \mathrm{k} \Omega}$ recorded $(201 \mathrm{mV})$. To compare the oxygen fluxes gained from the MFC experiments and microelectrodes, the geometric area of the soil cathode was assumed to be equivalent to the root area in contact with the soil cathode and that the oxygen depletion rate on the soil cathode was $20.6 \mathrm{pmol} \mathrm{cm} \mathrm{cm}^{-2} \mathrm{~s}^{-1}$. This value is comparable to the oxygen efflux rate detected by the $\mathrm{O}_{2}$ microelectrode $\left(<40 \mathrm{pmol} \mathrm{cm}^{-2} \mathrm{~s}^{-1}\right)$ which supports the hypothesis that the cathode of an SMFC can be used as a sensor for oxidized material.

The oxygen flux pattern along rice roots supports the second hypothesis that young rice roots were able to excrete more oxygen than the mature or aging rice roots. Significant oxygen effluxes behind root tips along adventitious roots were also found in other rice genotypes when raised in a stagnant deoxygenated nutrient solution (Colmer, 2002). Only a few studies have investigated the redox potential or oxygen density in plant rhizosphere. Of these, marked increases in redox potential were found close to rice root tips (Flessa and Fischer, 1992), but oxidized areas were discovered

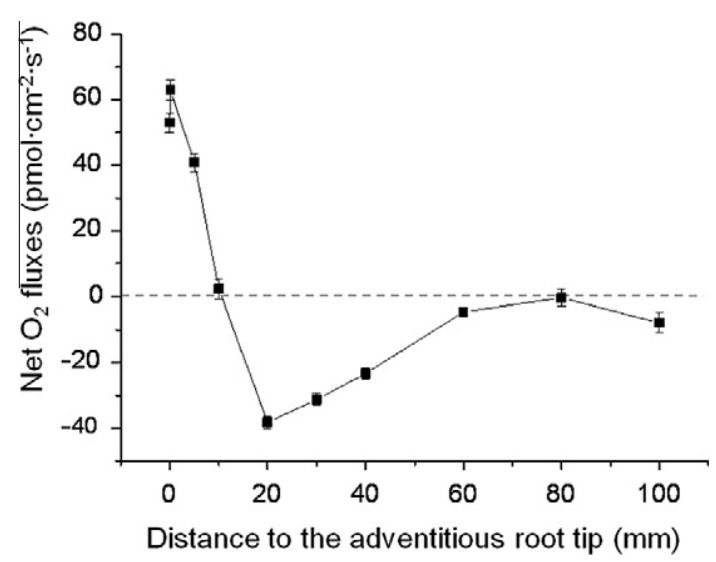

Fig. 4. Net oxygen flux profiles along rice adventitious root on hypoxia condition. Positive value means influx into roots; negative value means efflux out of roots. 
to exist along the entirety of the active root (Schmidt et al., 2010). For seagrass $Z$. marina, the oxygen concentration along its roots was highest in the region 2-4 mm behind the root tip (Frederiksen and Glud, 2006).

\subsection{The implication of a biocathode in the plant rhizosphere}

A thick soil layer was needed to prevent oxygen permeation to the anode in SMFCs. For example, He et al., (2009) designed a phototrophic SMFC with a cathode hung ca. $12 \mathrm{~cm}$ above an anode and a $5 \mathrm{~cm}$ soil layer between the air cathode and anode (Kaku et al., 2008). The distance between the air cathode and the anode in an SMFC often leads to changes in internal resistance, with a larger distance resulting in greater resistance (Rismani-Yazdi et al., 2008). The biocathode using plant roots excreted oxygen as an electron acceptor which allowed for a decrease in the distance between the two electrodes.

\section{Conclusions}

In summary, the oxygen excreted by rice roots has proved to be a viable alternative source of electron acceptors for SMFCs. A soil cathode has comparable efficiency to an air cathode, but has the advantage of a shorter distance between the cathode and anode because it can be placed directly in the soil. By counting the electrons transferred to soil cathode, the oxygen efflux from rice roots was able to be calculated. This study can aid in future research aimed at developing new kinds of SMFCs, as well as studies evaluating the effect of radius oxygen loss on ecological functions in wetlands.

\section{Acknowledgements}

We are grateful to the anonymous reviewers for their useful criticism and suggestions for improvement. We also thank Prof. Jun Yang for his identification of algae and Ms. Laura Webb for reviewing the English usage. The research has received funding from the National Science Foundation of China (Grant No. 41090280) and the Knowledge Innovation Program of CAS (KZCX2-EW-402).

\section{Appendix A. Supplementary data}

Supplementary data associated with this article can be found, in the online version, at doi:10.1016/j.biortech.2011.10.040.

\section{References}

Ajayi, F.F., Kim, K.-Y., Chae, K.-J., Choi, M.-J., Kim, I.S., 2010. Effect of hydrodynamic force and prolonged oxygen exposure on the performance of anodic biofilm in microbial electrolysis cells. Int. J. Hydrogen Energy 35, 3206-3213.

Armstrong, W., Justin, S.H.F.W., Beckett, P.M., Lythe, S., 1991. Root adaptation to soil waterlogging. Aquat. Bot. 39, 57-73.

Chen, Z., Zhu, Y.-G., Liu, W.-J., Meharg, A.A., 2004. Direct evidence showing the effect of root surface iron plaque on arsenite and arsenate uptake into rice (Oryza sativa) roots. New Phytol. 165, 91-97.

Clauwaert, P., Rabaey, K., Aelterman, P., de Schamphelaire, L., Pham, T.H., Boeckx, P., Boon, N., Verstraete, W., 2007. Biological denitrification in microbial fuel cells. Environ. Sci. Technol. 41, 3354-3360.
Colmer, T.D., 2002. Aerenchyma and an inducible barrier to radial oxygen loss facilitate root aeration in upland, paddy and deep-water rice (Oryza sativa L.). Ann. Bot. 91, 301-309.

De Schamphelaire, L., Bossche, L.V.D., Dang, H.S., Höfte, M., Boon, N., Rabaey, K., Verstraete, W., 2008. Microbial fuel cells generating electricity from rhizodeposits of rice plants. Environ. Sci. Technol. 42, 3053-3058.

Emerson, D., Weiss, J.V., Megonigal, J.P., 1999. Iron-oxidizing bacteria are associated with ferric hydroxide precipitates (Fe-plaque) on the roots of wetland plants. Appl. Environ. Microbiol. 65, 2758-2761.

Flessa, H., Fischer, W.R., 1992. Plant-induced changes in the redox potentials of rice rhizospheres. Plant Soil 143, 55-60.

Frederiksen, M.S., Glud, R.N., 2006. Oxygen dynamics in the rhizosphere of Zostera marina: a two-dimensional planar optode study. Limnol. Oceanogr. 51, 10721083

Gao, S., Tanji, K.K., Scardaci, S.C., 2011. Impact of rice straw incorporation on soil redox status and sulfide toxicity. Agron. J. 96, 70-76.

He, Z., Angenent, L.T., 2006. Application of bacterial biocathodes in microbial fuel cells. Electroanalysis 18, 2009-2015.

He, Z., Kan, J., Mansfeld, F., Angenent, L.T., Nealson, K.H., 2009. Self-sustained phototrophic microbial fuel cells based on the synergistic cooperation between photosynthetic microorganisms and heterotrophic bacteria. Environ. Sci. Technol. 43, 1648-1654.

Helder, M., Strik, D.P.B.T.B., Hamelers, H.V.M., Kuhn, A.J., Blok, C., Buisman, C.J.N., 2010. Concurrent bio-electricity and biomass production in three plantmicrobial fuel cells using Spartina anglica, Arundinella anomala and Arundo donax. Bioresour. Technol. 101, 3541-3547.

Kaku, N., Yonezawa, N., Kodama, Y., Watanabe, K., 2008. Plant/microbe cooperation for electricity generation in a rice paddy field. Appl. Microbiol. Biotechnol. 79, 43-49.

Kotula, L., Steudle, E., 2009. Measurements of oxygen permeability coefficients of rice (Oryza sativa L.) roots using a new perfusion technique. J. Exp. Bot. 60, 567580 .

Liu, W.-J., Zhu, Y.-G., Smith, F.A., Smith, S.E., 2004. Do phosphorus nutrition and iron plaque alter arsenate (As) uptake by rice seedlings in hydroponic culture? New Phytol. 162, 481-488.

Lovley, D.R., 2006. Microbial fuel cells: novel microbial physiologies and engineering approaches. Curr. Opin. Biotechnol. 17, 327-332.

Marschner, P., Kandeler, E., Marschner, B., 2003. Structure and function of the soil microbial community in a long-term fertilizer experiment. Soil Biol. Biochem. $35,453-461$.

Pang, J.Y., Newman, I., Mendham, N., Zhou, M., Shabala, S., 2006. Microelectrode ion and $\mathrm{O}_{2}$ fluxes measurements reveal differential sensitivity of barley root tissues to hypoxia. Plant Cell Environ. 29, 1107-1121.

Rismani-Yazdi, H., Carver, S.M., Christy, A.D., Tuovinen, O.H., 2008. Cathodic limitations in microbial fuel cells: an overview. J. Power Sources 180, 683-694.

Rosenbaum, M., He, Z., Angenent, L.T., 2010. Light energy to bioelectricity: photosynthetic microbial fuel cells. Curr. Opin. Biotechnol. 21, 259-264.

Rubinigg, M., Stulen, I., Elzenga, J.T.M., Colmer, T.D., 2002. Spatial patterns of radial oxygen loss and nitrate net flux along adventitious roots of rice raised in aerated or stagnant solution. Funct. Plant Biol. 29, 1475-1481.

Schmidt, H., Eickhorst, T., Tippkötter, R., 2010. Monitoring of root growth and redox conditions in paddy soil rhizotrons by redox electrodes and image analysis. Plant Soil 341, 221-232.

Segers, R., 1998. Methane production and methane consumption: a review of processes underlying wetland methane fluxes. Biogeochemistry 41, 23-51.

Tanji, K.K., Gao, S., Scardaci, S.C., Chow, A.T., 2003. Characterizing redox status of paddy soils with incorporated rice straw. Geoderma 114, 333-353.

Timmers, R.A., Strik, D.P.B.T.B., Hamelers, H.V.M., Buisman, C.J.N., 2010. Long-term performance of a plant microbial fuel cell with Spartina anglica. Appl. Microbiol. Biotechnol. 86, 973-981.

Trolldenier, G., 1973. Secondary effects of potassium and nitrogen nutrition of rice: change in microbial activity and iron reduction in the rhizosphere. Plant Soil 38, 267-279.

Van Bodegom, P., Goudriaan, J., Leffelaar, P., 2001. A mechanistic model on methane oxidation in a rice rhizosphere. Biogeochemistry 55, 145-177.

Weiss, J.V., David, E., Backer, S.M., Megonigal, J.P., 2011. Enumeration of Fe(II)oxidizing and $\mathrm{Fe}(\mathrm{III})$-reducing bacteria in the root zone of wetland plants: implications for a rhizosphere iron cycle. Biogeochemistry 64, 77-96.

Yuan, Y., Conrad, R., Lu, Y., 2009. Responses of methanogenic archaeal community to oxygen exposure in rice field soil. Environ. Microbiol. Rep. 1, 347-354.

Zhao, F., Slade, R.C.T., Varcoe, J.R., 2009. Techniques for the study and development of microbial fuel cells: an electrochemical perspective. Chem. Soc. Rev. 38, 1926-1939. 